The Economic and Social Review, Vol. 41, No. 1, Spring, 2010, pp. 1-20

\title{
The Measurement of Child Costs: Evidence from Ireland*
}

\author{
OLIVIER BARGAIN \\ University College Dublin
}

OLIVIER DONNI

Université Cergy-Pontoise, THEMA

MONNET GBAKOU

Geary Institute, University College Dublin

\begin{abstract}
We apply an extension of the Rothbarth approach to estimate the share of household resources accruing to children (i.e., the cost of children) in Ireland. The method also allows us to identify the economies of scale in the household and indifference scales in Lewbel (2003)'s sense. A practical aspect of the present approach is that it does not require price variation. The identification of the children's share requires the observation of adult-specific goods as in the traditional Rothbarth method. We compare our findings to previous results for Ireland.
\end{abstract}

The authors dedicate this paper to the memory of Dr Eoghan Garvey.

*Acknowledgements: Olivier Bargain is affiliated to University College Dublin, IZA, the Geary Institute, the ESRI and CHILD. Olivier Donni is affiliated to the Universite Cergy-Pontoise, THEMA and IZA. Monnet Gbakou was affiliated to the Geary Institute when this paper was written. We thank Martin Browning for useful comments. We also thank participants to seminars at IZA (Bonn), BETA (Strasbourg), CEPS-INSTEAD (Luxembourg), Combat Poverty Agency (Dublin), CORE (Louvain-la-Neuve) and THEMA (Cergy-Pontoise). We are very grateful to ANR08-FASH-18 and the Combat Poverty Agency, Dublin, for financial support. All errors or omissions remain ours. Correspondence: Olivier Bargain, UCD, Belfield, Dublin, Ireland. Phone: +353-17168357. E-mail: olivier.bargain@ucd.ie

Paper delivered at the Twenty-Third Annual Conference of the Irish Economic Association, Blarney, Co. Cork, 2009. 


\section{INTRODUCTION}

$\mathrm{T}$ The economic measurement of the cost of children has received a lot of attention in the literature. ${ }^{1}$ While it is intimately related to the literature on equivalence scales, it also has its own important policy implications. One example is the possibility of determining child support payments by a noncustodial parent to a custodial parent in the event of divorce. Another field of application is the direct measure of child poverty. ${ }^{2}$ It is crucial in Ireland where, like in other English speaking countries, rates of child poverty tend to be particularly high (see Micklewright, 2004; Callan et al., 2007). ${ }^{3}$

Several empirical approaches have been suggested to infer the cost of children from expenditure surveys. In particular, the traditional Rothbarth (1943) method is based on the intuition that goods exclusively consumed by adults yield some information on what children receive from their parents. This approach has been formalised by several authors, including Gronau (1991) and Lazear and Michael (1988), and extended by Bargain and Donni (2009) to account for economies of scale in the household. The latter approach is closely related to the most recent developments of the literature on collective models. ${ }^{4}$ Precisely, recent papers suggest a complete identification of scale economies and the household sharing rule based on the estimation of individual demand functions (Browning et al., 2006) or individual Engel curves (Lewbel and Pendakur, 2008) on data for single individuals. 5 The identification crucially relies on the assumption that household demands differ from those of single individuals only because of (some) jointness of consumption and sharing within the household. While these authors focus on scale economies and resource sharing within childless couples, Bargain and Donni (2009) extend the approach to families with children and retrieve the sharing rule between wife, husband and children. ${ }^{6}$ Browning et al. (2006) account for economies of scale using a (price) transformation à la Barten (1964); alternatively, Lewbel and Pendakur (2008) and Bargain and Donni (2009) make an independence of base assumption that allows them to achieve

\footnotetext{
${ }^{1}$ See Browning (1992) and Lewbel (1997) for a survey.

${ }^{2}$ Financial resources channeled to children are not only of importance for their present well-being but may also have pervasive effect over the lifetime.

${ }^{3}$ According to Layte et al. (2006), 26 per cent of children under 14 years of age are at risk of poverty, i.e., in households with income below 60 per cent of median equivalised income, against an average of 20 per cent for the EU-25. According to CSO (2006), one in ten children is in consistent poverty (i.e., in a low income household and deprived of basic necessities).

${ }^{4}$ See Donni (2008) and Chiappori and Donni (2010) for a survey.

5 The early paper of Conniffe (1992) already went in the direction of Browning et al. (2006) and can be considered a precursor to this literature.

${ }^{6}$ Research on collective models has so far ignored the role of children. The sole exceptions, to our knowledge, are Blundell et al. (2005), Bourguignon (1999) and Menon and Perali (2007).
} 
identification without price variation. This is of particular relevance for countries in which spatial or time variation in prices is limited.

The present paper applies the approach of Bargain and Donni (2009) to Irish data, and focuses on three types of households: single individuals (either male or female), childless couples and couples with one child. We consider only families with young children, for whom the assumption that children do not have any decision-making power is reasonable. Therefore, the resource share accruing to children in this setting can be equally interpreted as the cost of children for (benevolent) parents. The identification of children's share relies on the observation of adult clothing while that of adult shares and scale economies is based on estimations of individual Engel curves on single individuals. We compare our findings to previous studies for Ireland, in particular those applying the traditional Rothbarth method.

In Section II, we briefly summarise the model of Bargain and Donni (2009). Section III describes the empirical implementation and data selection. Section IV reports the results and Section V concludes.

\section{THE MODEL}

We consider three household types $n$, namely a single individual $(n=1)$, a couple without children $(n=2)$ and a couple with one child $(n=3)$. Superscript $k=1, \ldots, K$ denotes goods while individuals are indexed by subscript $j$. By convention, we suppose that $j=1$ is a male adult, $j=2$ is a female adult and $j=3$ is a child. The log total expenditure in a household is denoted by $x$ and the vector of $\log$ prices by $\boldsymbol{p}$. We assume that total expenditure $\exp (x)$ is divided between household members according to some rule. Precisely, individual $j$ living in household $n$ receives a resource share $\eta_{j, n}(\boldsymbol{p}, x)$ of total expenditure $\exp (x)$. These shares may, in general, depend on prices and total expenditure. ${ }^{7}$ The shares of all members are positive and sum up to unity, i.e., $\sum_{j=1}^{n} \eta_{j, n}(\boldsymbol{p}, x)=1$. The "basic" budget share of individual $j$ for good $k$ is denoted $w_{j}^{k}$; that is, if person $j$ is living alone, he/she spends the fraction $w_{j}^{k}$ of total expenditure $\exp (x)$ on good $k$. If he/she is living with other persons (parents, children or spouse), his/her basic budget share functions change in a way that reflects scale economies and resource sharing, as described in detail in what follows. The share spent by household $n$ on good $k$ is denoted by $W_{n}{ }^{k} .8$

\footnotetext{
${ }^{7}$ For instance, we can imagine that the resources accruing to the child vary when the price of child goods changes (see also Bargain and Donni, 2008, on this point).

${ }^{8}$ Similar notations are used hereafter to represent budget share functions, whose arguments are specified as we go along.
} 
Multi-person households $(n>1)$ are characterised by economies of scale due to the sharing and jointness of consumption in the household. Following Lewbel and Pendakur (2008) and Bargain and Donni (2009), we exploit the Independence of Base (IB) assumption, that we introduce formally below, to represent these scale economies. Denote $V_{j}(\boldsymbol{p}, \phi)$ the indirect utility of individual $j$ endowed with $\log$ resources $\phi$, that is, $\phi$ corresponds to total expenditure $x$ in a single household $(n=1)$ and to a scaled version of the share of total expenditure $x+\log \eta_{j, n}$ in a multi-person household $(n>1)$. More precisely, for each person $j$ living in a household of type $n>1$, we assume that there exists a scalar-valued function $s_{j, n}(\boldsymbol{p})$ such that the indifference curves of individual $j$ satisfy the condition:

$$
U_{j}=V_{j}\left(\boldsymbol{p}, x+\log \eta_{j, n}(\boldsymbol{p}, x)-\log s_{j, n}(\boldsymbol{p})\right)
$$

for any level of $\log$ individual expenditure $x+\log \eta_{j, n}(\boldsymbol{p}, x)$. Clearly, $\eta_{j, 1}(p, x)=$ $s_{j, 1}(\boldsymbol{p})=1$ for a single individual $(n=1)$. Intuitively, Equation (1) supposes that economies of scale can be summarised by a simple income effect represented by the deflator $s_{j, n}(\boldsymbol{p})$. The latter measures the cost savings experienced by person $j$ resulting from scale economies in the household. The IB assumption refers to the fact that scale economies are assumed to be independent of the base expenditure (and hence utility) level at which they are evaluated. This assumption is similar to the IB restriction in the equivalence scale literature, and can be justified in the same way, but it concerns individual utility functions rather than aggregated household utility functions.

Denote $\log I_{j, n}=\log s_{j, n}(\boldsymbol{p})-\log \eta_{j, n}(\boldsymbol{p}, x)$ so that for $n>1$, Equation (1) can be written as:

$$
U_{j}=V_{j}\left(\boldsymbol{p}, x-\log I_{j, n}(\boldsymbol{p}, x)\right) .
$$

The term $I_{j, n}$ is an indifference scale as defined by Lewbel (2003) and Browning et al. (2006). Indifference scales differ from ordinary household equivalence scales, which attempt to compare the utility of an individual to the utility of a household and hence suffer from the identification problems associated with interpersonal comparisons (Pollak and Wales, 1992). In contrast, an indifference scale compares the same individual in two different situations: living alone and living in a household. It represents the income adjustment applied to person $j$ when living alone for her/him to reach the same indifference curve as when living in a multi-person household (and consuming a share $\eta_{j, n}$ of total resources while benefiting from scale economies as represented by $s_{j, n}$ ).

Applying Roy's identity to Equation (1), it is easy to show that individual $j$ 's budget share function on good $k$ can be written: 


$$
\omega_{j, n}^{k}(\boldsymbol{p}, x)=d_{j, n}^{k}(\boldsymbol{p})+w_{j}^{k}\left(\boldsymbol{p}, x-\log I_{j, n}(\boldsymbol{p}, x)\right)
$$

where

$$
d_{j}^{k}(\boldsymbol{p})=\frac{\partial \log s_{j, n}(\boldsymbol{p})}{\partial p^{k}}
$$

is the elasticity of $s_{j, n}$ with respect to the $k$-th price. The consequence of the IB assumption in the present context is that the budget share functions of person $j$ when living in a household differ from when alone only in that they are translated over log household resources $x$ by log $I_{j, n}$ and over each $w_{j}^{k}$ by $d_{j, n}^{k}$.

We now suppose that data are observed in a unique price regime: the vector of prices $\boldsymbol{p}$ is constant and can be taken out of Equation (3). This simplification is allowed by the IB assumption and is well adapted for countries where price variation is small. ${ }^{9}$ Although the scale economies do not depend on the base expenditure, they may nonetheless vary with the demographic structure of the household. Thus, a vector $\mathbf{z}$ of household sociodemographic variables is introduced in Equation (3). We can now introduce formally the IB assumption in a framework with no price variation:

A.1. The individual preferences and the household technology satisfy the IB assumption. That is, the budget share on good $k$ of person $j$ living in household $n$ is written:

$$
\omega_{j, n}^{k}(x, \mathbf{z})=d_{j, n}^{k}\left(\mathbf{z}_{j}\right)+w_{j}^{k}\left(x-\log I_{j, n}(x, \mathbf{z}), \mathbf{z}_{j}\right)
$$

where $\log I_{j, n}(x, \mathbf{z})=\log s_{j, n}\left(\mathbf{z}_{j}\right)-\log \eta_{j, n}(x, \mathbf{z})$ is the log deflator of total expenditure which combines the scaling effect $s_{j, n}$ and resource sharing $\eta_{j, n}$.

The left-hand side of Equation (4) represents the "reduced-form" budget share of person $j$ on good $k$ as a function of (log) household resources $x$ and household characteristics $\mathbf{z}$. The right-hand side puts some structure on the budget share as a result of the IB restriction. The individual budget share function $w_{j}^{k}$ depends on person $j$ 's individual resources adjusted by the scaling factor $s_{j, n}$ and on individual-specific characteristics $\mathbf{z}_{j}$. This share is also translated by the price elasticity of scale economies. The scaling effect $s_{j, n}$, and subsequently its price elasticity $d_{j, n}^{k}$, depend on individual characteristics $\mathbf{z}_{j}$. The resource share $\eta_{j, n}$ depends on household total expenditure and on the vector of household characteristics $\mathbf{z}$, which nests the individual character-

\footnotetext{
${ }^{9}$ This is the case for our application on Irish data, since there is little spatial variation in prices, contrary to large countries like Canada or the US, and little time variation (only three crosssections are available over the past twenty years: 1995, 1999 and 2005).
} 
istics $\mathbf{z}_{j}$ of all members $j$ and may also incorporate variables that govern the resource sharing rule in the household (i.e., distribution factors, see Browning et al., 2006). One important candidate for these variables is the ratio of spouses' exogenous incomes in as much as the household bargaining power of spouses depends on what they earn.

One word of reservation is needed here. Changes in the demographic structure of the household may also generate modification of preferences and externalities in consumption that are not explicitly accounted for by the IB assumption. Note that the model of Lewbel and Pendakur (2008) exhibits basically the same problem even if it is perhaps more critical as soon as children are incorporated in the analysis. In particular, the apparition of a child in the household may generate important externalities. For example, the parents may decide to stop smoking and to change their leisure activities. Whether the deflator $s_{j, n}(\boldsymbol{z})$ can conveniently represent modifications of preferences and externalities in consumption is a complicated question which is beyond the scope of the present paper. If the answer is negative, however, the interpretation of the empirical results we make may be biased. We have to keep in mind these potential limitations of the model.

For each good $k$, we can write total household expenditure as the sum of individual expenditure on that good. Dividing this identity by total outlay $\exp (x)$, we obtain directly the household budget share function for good $k$ :

$$
W_{n}^{k}(x, \mathbf{z})=\sum_{j=1}^{n} \eta_{j, n}(x, \mathbf{z}) \cdot \omega_{j, n}^{k}(x, \mathbf{z}) .
$$

This is simply the sum of individual budget share functions of all household members weighted by their individual resource share. Using Equation (4), this can be written as:

$$
W_{n}^{k}(x, \mathbf{z})=\sum_{j=1}^{n} \eta_{j, n}(x, \mathbf{z})\left[\mathrm{d}_{j, n}^{k}\left(\mathbf{z}_{j}\right)+w_{j}^{k}\left(x-\log \mathrm{I}_{j, n}(x, \mathbf{z}), \mathbf{z}_{j}\right)\right],
$$

where individual budget shares are translated both in budget shares and logexpenditure. As previously described, the translations are meaningful model parameters: translations in log-expenditure are individual indifference scales while translation in budget shares are scales economy price elasticities.

The complete identification results are presented in Bargain and Donni (2009). Hereafter, we simply provide the main intuition of the proofs in a slightly simplified context. First, it is important to notice that the central element in (4) and (6) is the basic budget share function $w_{j}^{k}\left(\cdot, \mathbf{z}_{j}\right)$, that is, the 
share of good $k$ chosen by an individual $j$ endowed with characteristics $\mathbf{z}_{j}$. This function is identical for single individuals or adults in multi-person households. For an adult living in a couple $(n=2)$, his/her "basic budget" share function is simply affected by resource sharing and scale economies in the household. That is to say, differences between an individual's bundle of goods consumed as a single versus within a household are assumed to be due to partially joint consumption, resource sharing and to changes in total resources. As argued by Gronau (1988), this assumption, as strong as it may seem, is necessary to make the comparison of individuals living in different households possible. Hence, the basic share function is directly retrieved using estimates from single individuals, for whom $W_{1}^{k}(x, \mathbf{z})=w_{j}^{k}\left(x, \mathbf{z}_{j}\right)$.

To identify the household technology and the shares of income, the following additional assumption will be used:

A.2. The resource sharing functions are independent of total household expenditure, that is, $\eta_{j, n}(x, \mathbf{z})=\eta_{j, n}(\mathbf{z})$ for $j=1,2,3$ and $n=2,3$.

From the knowledge of the "basic" share functions, it is then possible to identify household technology $s_{j, 2}$ and the shares of income $\eta_{j, 2}$ (for $j=1,2$ ), as demonstrated in Bargain and Donni (2009) and Lewbel and Pendakur (2008). The idea is simple. Suppose first that $w_{j}^{k}\left(\cdot, \mathbf{z}_{j}\right)$ are known functions. Then, when $\mathbf{z}$ is maintained constant, there exist (generically) unique values for $s_{j, 2}$ and $\eta_{j, 2}$ such that Equation (6) with $n=2$ is satisfied for any value of $x$ within its domain. Note that assumption A.2 is potentially a strong restriction but it is not absolutely essential (it could be abandoned at the expense of some complications - see Bargain and Donni, 2009). Moreover, it can be mitigated by including measures of household wealth other than total expenditure in income shares, as we do in the last part of the empirical section.

Finally, for a couple with a child $(n=3)$, the complete identification of resource shares requires the following assumption:

A.3. There exists at least one exclusive good for adults, that is, a good which is consumed by parents but not by children.

This identification assumption is also made in Gronau (1991) and is at the basis of the Rothbarth intuition. If assumption A.3 is satisfied, the parent's shares of income and economies of scale can be recovered from the observation of the budget share functions of adult goods. Note that, for the child, certain parameters cannot be identified. They can be normalised without loss of generality, precisely: 


$$
d_{3,3}^{k}\left(\mathbf{z}_{3}\right)=0, s_{3,3}\left(\mathbf{z}_{3}\right)=1
$$

since children are not observed living alone. The child's share of total resources is then retrieved directly as $\eta_{3,3}(\mathbf{z})=1-\eta_{1,3}(\mathbf{z})-\eta_{2,3}(\mathbf{z})$.

\section{EMPIRICAL IMPLEMENTATION}

\subsection{Functional Form and Estimation Method}

For the estimation, we suggest a parameterisation that balances flexibility and empirical tractability. The first component, which appears in the specification of the different demographic groups, is the basic budget share function. For adults, we consider the following functional form:

$$
w_{j}^{k}\left(\phi, \mathbf{z}_{j}\right)=a_{j}^{k 0}+\mathbf{a}_{j}^{k} \mathbf{z}_{j}+\left(\phi-\mathbf{e}_{j}^{\prime} \mathbf{z}_{j}\right) b_{j}^{k}+\left(\phi-\mathbf{e}_{j}^{\prime} \mathbf{z}_{j}\right)^{2} c_{j}^{k}
$$

for $j=1,2$ and $k=1, \ldots K$, with $\phi$ a given level of log individual expenditures (equal to $x$ for a single $n=1$ and to $x-I_{j, n}(\mathbf{z})$ for adult $j$ in a family $n=2,3$ ), parameters $a_{j}^{k 0}, b_{j}^{k}, c_{j}^{k}$ and vectors of parameters $\mathbf{a}_{j}^{k}$ and $\mathbf{e}_{j}$. The vectors of adult characteristics $\mathbf{z}_{1}$ and $\mathbf{z}_{2}$ include age ("above 35" dummy), education ("tertiary education" dummy), and dummies for car ownership and urban. The parameters are gender specific (i.e., are indexed $j=1$ for men and $j=2$ for women) but do not depend on the demographic type $n$ since the "basic" budget share functions are the same for single women (men) and for women (men) living in a couple. For children, the vector $\mathbf{z}_{3}$ includes a gender dummy in order to differentiate the cost of boys and girls; it could also reflect differences in children's age - but in the current application, we focus on the group of children aged 0-4 years so that age variables have not been included.

We now turn to the specification of the household budget share functions. For single male and female adults, they coincide with the basic budget share functions specified above, that is,

$$
W_{1}^{k}(x, \mathbf{z})=w_{j}^{k}\left(x, \mathbf{z}_{j}\right)+\varepsilon_{1}^{k},
$$

where $\varepsilon_{1}{ }^{k}$ is an error term. For multi-person households $\mathrm{n}>1$, the household budget share functions,

$$
\mathrm{W}_{n}{ }^{k}(x, \mathbf{z})=\sum_{j=1}^{n} \eta_{j, n}(\mathbf{z})\left[d_{j, n}^{k}\left(\mathbf{z}_{j}\right)+w_{j}^{k}\left(x-\log \mathrm{I}_{j, n}(\mathbf{z}), \mathbf{z}_{j}\right)\right]+\varepsilon_{n}{ }^{k},
$$

comprise the individual functions $w_{j}^{k}$ as already specified and three other components. First, the resource shares are specified using the logistic form: 


$$
\eta_{j, n(\mathbf{z})}=\frac{\exp \left(\varphi_{j, n}^{\prime} \mathbf{z}\right)}{\sum_{j=1}^{n} \exp \left(\varphi_{j, n}^{\prime} \mathbf{z}\right)}
$$

where $\varphi_{j, n}^{\prime}$ is a vector of parameters. The parameters of the first individual are set to zero for normalisation. Vector $\mathbf{z}$ includes the sets of individual characteristics $\mathbf{z}_{j}$ for $j=1, \ldots n$ and a distribution factor, the wage ratio. The latter is defined as the ratio of wife's over husband's earnings expressed in full-time equivalent (as explained below, we restrict our sample to households where all adults are in work). ${ }^{10}$ Second, the log scale function that translates expenditure within the basic budget shares can be written as:

$$
\log s_{j, n}\left(\mathbf{z}_{j}\right)=\beta_{j, n}^{0}+\beta_{j, n}^{\prime} \mathbf{z}_{j}
$$

where $\beta_{j, n}^{0}$ and $\beta_{j, n}^{\prime}$ are parameters. In principle, it can vary with all the variables used in preferences (vector $\mathbf{z}_{j}$ ). Finally, the scale function that translates the basic budget shares $d_{j, n}^{k}\left(\mathbf{z}_{j}\right)$ is a price elasticity. Price effects are typically difficult to measure, so it is all the more difficult to conceive that their interaction with demographics can be captured in any plausible way. Therefore, we restrict these terms to be constant, that is:

$$
d_{j, n}^{k}\left(\mathbf{z}_{j}\right)=d_{j, n}^{0 k}
$$

Since budget shares sum up to one, equations for good $K$ are unnecessary. The household budget share functions for $K-1$ goods and for the three demographic groups are estimated simultaneously. The complete model is estimated by the iterated SURE method. The first variant of the model presented hereafter (model A) imposes some exclusion restrictions on the demographic variables while model $\mathrm{B}$ is the complete model; model $\mathrm{C}$ is similar to Gronau (1991), that is, corresponds to a structural Rothbarth approach without scale economies. Finally, the last model (variant D) accounts for the likely correlation between the error terms $\varepsilon_{n}{ }^{k}$ in each budget share function and the log total expenditure by augmenting the specification with the errors $\hat{v}_{n, x}$ and $\hat{v}_{n, x^{2}}$ obtained from reduced form estimations of $x$ and $x^{2}$ respectively on all exogenous variables used in the model plus some excluded instruments (see Blundell and Robin, 1999, 2000, Banks et al., 1997). For the latter, we choose log household gross income and its square.

\footnotetext{
${ }^{10} \mathrm{We}$ could also include the difference in spouses' education level (schooling years) or age. Since education and age are already in the $\mathbf{z}_{j}$ vector of adults, then vector $\mathbf{z}$ automatically accounts for these differences - even if only through age and education dummies.
} 
Table 1: Descriptive Statistics

\begin{tabular}{|c|c|c|c|c|}
\hline & $\begin{array}{l}\text { Single } \\
\text { Women }\end{array}$ & $\begin{array}{l}\text { Single } \\
\text { Men }\end{array}$ & $\begin{array}{l}\text { Childless } \\
\text { Couples }\end{array}$ & $\begin{array}{c}\text { Couples } \\
\text { and } 1 \text { Child }\end{array}$ \\
\hline Age (head) & $\begin{array}{l}45.2 \\
(9.9)\end{array}$ & $\begin{array}{c}43.8 \\
(10.7)\end{array}$ & $\begin{array}{c}42.4 \\
(11.6)\end{array}$ & $\begin{array}{l}38.0 \\
(7.9)\end{array}$ \\
\hline Years of education (head) & $\begin{array}{l}15.5 \\
(3.5)\end{array}$ & $\begin{array}{l}14.4 \\
(3.4)\end{array}$ & $\begin{array}{l}14.6 \\
(3.6)\end{array}$ & $\begin{array}{l}14.6 \\
(3.1)\end{array}$ \\
\hline Living in city & $\begin{array}{l}0.86 \\
(0.34)\end{array}$ & $\begin{array}{c}0.72 \\
(0.45)\end{array}$ & $\begin{array}{c}0.69 \\
(0.46)\end{array}$ & $\begin{array}{c}0.67 \\
(0.47)\end{array}$ \\
\hline Tenant & $\begin{array}{c}0.15 \\
(0.35)\end{array}$ & $\begin{array}{c}0.16 \\
(0.36)\end{array}$ & $\begin{array}{c}0.12 \\
(0.32)\end{array}$ & $\begin{array}{l}0.06 \\
(0.25)\end{array}$ \\
\hline Have a car & $\begin{array}{c}0.84 \\
(0.37)\end{array}$ & $\begin{array}{c}0.82 \\
(0.38)\end{array}$ & $\begin{array}{c}0.95 \\
(0.21)\end{array}$ & $\begin{array}{c}0.97 \\
(0.18)\end{array}$ \\
\hline Wage ratio (wf/wm) & n.a. & n.a. & $\begin{array}{c}0.90 \\
(0.50)\end{array}$ & $\begin{array}{c}0.93 \\
(0.52)\end{array}$ \\
\hline Total expenditure (EUR/week) & $\begin{array}{c}477 \\
(235)\end{array}$ & $\begin{array}{c}412 \\
(220)\end{array}$ & $\begin{array}{l}700 \\
(305)\end{array}$ & $\begin{array}{c}770 \\
(306)\end{array}$ \\
\hline Budget shares & & & & \\
\hline Food & $\begin{array}{c}0.18 \\
(0.08)\end{array}$ & $\begin{array}{c}0.21 \\
(0.09)\end{array}$ & $\begin{array}{c}0.22 \\
(0.08)\end{array}$ & $\begin{array}{c}0.22 \\
(0.07)\end{array}$ \\
\hline Alcohol and tobacco & $\begin{array}{c}0.06 \\
(0.06)\end{array}$ & $\begin{array}{c}0.10 \\
(0.10)\end{array}$ & $\begin{array}{c}0.07 \\
(0.06)\end{array}$ & $\begin{array}{c}0.07 \\
(0.06)\end{array}$ \\
\hline Men's clothing & $\begin{array}{c}0.00 \\
(0.00)\end{array}$ & $\begin{array}{c}0.03 \\
(0.08)\end{array}$ & $\begin{array}{c}0.02 \\
(0.05)\end{array}$ & $\begin{array}{c}0.01 \\
(0.03)\end{array}$ \\
\hline Women's clothing & $\begin{array}{c}0.06 \\
(0.09)\end{array}$ & $\begin{array}{c}0.00 \\
(0.00)\end{array}$ & $\begin{array}{c}0.03 \\
(0.05)\end{array}$ & $\begin{array}{l}0.03 \\
(0.04)\end{array}$ \\
\hline Child's clothing & $\begin{array}{c}0.00 \\
(0.00)\end{array}$ & $\begin{array}{c}0.00 \\
(0.00)\end{array}$ & $\begin{array}{c}0.00 \\
(0.00)\end{array}$ & $\begin{array}{c}0.02 \\
(0.02)\end{array}$ \\
\hline Transport & $\begin{array}{c}0.12 \\
(0.09)\end{array}$ & $\begin{array}{c}0.13 \\
(0.10)\end{array}$ & $\begin{array}{c}0.14 \\
(0.08)\end{array}$ & $\begin{array}{c}0.13 \\
(0.08)\end{array}$ \\
\hline Leisure & $\begin{array}{c}0.14 \\
(0.08)\end{array}$ & $\begin{array}{c}0.15 \\
(0.11)\end{array}$ & $\begin{array}{c}0.16 \\
(0.10)\end{array}$ & $\begin{array}{c}0.14 \\
(0.08)\end{array}$ \\
\hline Household operations & $\begin{array}{l}0.10 \\
(0.07)\end{array}$ & $\begin{array}{c}0.09 \\
(0.08)\end{array}$ & $\begin{array}{c}0.10 \\
(0.07)\end{array}$ & $\begin{array}{l}0.11 \\
(0.07)\end{array}$ \\
\hline Personal goods and services & $\begin{array}{c}0.06 \\
(0.07)\end{array}$ & $\begin{array}{c}0.02 \\
(0.03)\end{array}$ & $\begin{array}{c}0.04 \\
(0.05)\end{array}$ & $\begin{array}{c}0.12 \\
(0.10)\end{array}$ \\
\hline Housing & $\begin{array}{l}0.05 \\
(0.04)\end{array}$ & $\begin{array}{c}0.07 \\
(0.06)\end{array}$ & $\begin{array}{c}0.05 \\
(0.03)\end{array}$ & $\begin{array}{c}0.05 \\
(0.03)\end{array}$ \\
\hline Sample size & 213 & 191 & 369 & 250 \\
\hline
\end{tabular}

Standard deviations are in brackets.

\subsection{Data}

Our sample is drawn from the 2005 Irish Household Budget Survey (HBS). This data is gathered from the third quarter 2004 to the end of 2005, but only a little price variation is witnessed over this period so that the HBS sample can be treated as cross-sectional data. We estimate the system of 
budget shares for $K=9$ non-durable commodities: food, vice goods (alcohol and tobacco), male and female clothing, transport, leisure, personal goods and services, household operation and a composite child good (child clothing and pocket money); the omitted good is housing costs (rent, observed for tenant or predicted for owners of their dwelling). ${ }^{11}$

The initial survey is composed of 6,884 households. We select households where adults are aged 25-64 years, which restricts the initial sample by 30 per cent. We only keep those comprising a childless single man or woman, childless married couples and married couples with one child aged 0-4 years (in all cases, we discard observations where other household members, relatives or not, are present. This restricts the initial sample by another 27 per cent. Since leisure is not modeled here, but is likely endogenous to consumption (and savings) decisions, we restrict our sample to working women and full-time working men. This discards another 28 per cent of the original sample. The final sample is composed of 1,023 observations and is described in Table 1.

\section{EMPIRICAL RESULTS}

\subsection{Estimations}

Table 2 reports the estimated economies of scale $s_{j, n}\left(\overline{\mathbf{z}}_{j}\right)$ for $j=1,2$ and resource shares $\eta_{j, n}\left(\overline{\mathbf{z}}_{j}\right)$ for $j=2,3$ evaluated at the sample mean, as well as their standard errors. ${ }^{12}$ Notice that deflators $s_{j, n}$ should, in principle, lie between 0.5 (complete jointness of consumption) and 1 (purely private consumption) in a couple if these terms are to be interpreted as reflecting scale economies. A deflator of .75 for (childless) couples means that the cost of living for a man (say) with a woman is 75 per cent of the cost he would experience, should he live alone.

We first consider results for childless couples. Reassuringly, point estimates reported in Table 2 are reasonable in magnitude, all located in the 0.5-1 range with only one exception (males in model D). Overall, we find that point estimates give scale economies between 0.43 and 0.76 for men and between 0.53 and 0.66 for women. These results correspond to slightly smaller

11 In the original data, a marginal proportion of single women reports nonzero expenditures on male clothing. In order to treat clothing as an assignable good, these expenditures are set to zero. The same is done for expenditures on female clothing by single men and expenditures on children by childless households.

12 Estimates for the hundreds of parameters of the model, comprising the coefficients of the basic budget share functions for each good and each variant of the model, are available upon request to the authors. 
Table 2: Estimation Results

\begin{tabular}{|c|c|c|c|c|c|}
\hline Model & & $\mathrm{A}$ & B & $\mathrm{C}$ & $\mathrm{D}$ \\
\hline \multirow{7}{*}{ Economies of Scale } & men, no child & $\begin{array}{c}0.76 \\
(0.16)\end{array}$ & $\begin{array}{c}0.63 \\
(0.15)\end{array}$ & 1.00 & $\begin{array}{c}0.43 \\
(0.13)\end{array}$ \\
\hline & men, 1 child & 0.69 & 0.63 & 1.00 & 0.53 \\
\hline & & $(0.20)$ & $(0.19)$ & & $(0.17)$ \\
\hline & women, no child & 0.55 & 0.61 & 1.00 & 0.61 \\
\hline & & $(0.12)$ & $(0.13)$ & & $(0.16)$ \\
\hline & women, 1 child & 0.48 & 0.56 & 1.00 & 0.53 \\
\hline & & $(0.16)$ & $(0.16)$ & & $(0.17)$ \\
\hline \multirow{11}{*}{ Sharing Rule } & wife's share (no child) & 0.51 & 0.55 & 0.54 & 0.63 \\
\hline & & $(0.07)$ & $(0.06)$ & $(0.04)$ & $(0.07)$ \\
\hline & wife's share (with girl) & 0.41 & 0.45 & 0.45 & 0.51 \\
\hline & & $(0.06)$ & $(0.07)$ & $(0.04)$ & $(0.08)$ \\
\hline & wife's share (with boy) & 0.39 & 0.44 & 0.45 & 0.48 \\
\hline & & $(0.06)$ & $(0.06)$ & $(0.04)$ & $(0.08)$ \\
\hline & girl's share & 0.22 & 0.20 & 0.18 & 0.18 \\
\hline & & $(0.07)$ & $(0.07)$ & $(0.04)$ & $(0.07)$ \\
\hline & boy's share & 0.20 & 0.19 & 0.17 & 0.23 \\
\hline & & $(0.06)$ & $(0.06)$ & $(0.04)$ & $(0.08)$ \\
\hline & & -0.066 & -0.070 & -0.099 & -0.012 \\
\hline \multirow{3}{*}{\multicolumn{2}{|c|}{ Wage ratio on child's share }} & $(0.047)$ & $(0.050)$ & $(0.063)$ & $(0.013)$ \\
\hline & & 0.026 & 0.030 & 0.010 & $0.084^{*}$ \\
\hline & & $(0.053)$ & $(0.050)$ & $(0.052)$ & $(0.030)$ \\
\hline \multirow{2}{*}{\multicolumn{2}{|c|}{ Girl dummy on child's share }} & 0.157 & 0.066 & 0.068 & $0.279 *$ \\
\hline & & $(0.110)$ & $(0.090)$ & $(0.088)$ & $(0.127)$ \\
\hline \multicolumn{2}{|l|}{ Objective function } & 8.8041 & 8.7870 & 8.8122 & 8.7094 \\
\hline \multicolumn{2}{|c|}{ Number of parameters } & 161 & 175 & 155 & 237 \\
\hline
\end{tabular}

Model A: dummies for car holders and urbaners in preference translator only.

Model B: these dummies included also in preference deflator, scale economies and sharing rule.

Model C: same as B but no scale economies (Rothbarth model).

Model D: same as B but with endogeneity of log expenditure allowed for in a quadratic way.

Notes: Goods are food, alcohol and tobacco, male and female clothing, transport, leisure, personal goods and services, household operation and child good (clothing and pocket money); the omitted good is housing. Demographics affecting preferences (i.e. translate and deflate the log expenditure) and scale economies (deflator) are: male and female age and education, a dummy for car ownership and one for urban/rural. Economies of scale and sharing rules are calculated at sample means. Standard errors in brackets. 
deflators, and hence slightly larger scale economies, than those reported in Lewbel and Pendakur (2008). ${ }^{13}$ However, the standard errors for the log deflators are large in both studies, and neither study can reject that deflators lie in the $.5-1$ range.

It is fair to say that parameters are imprecisely estimated and our results are sensitive to the specification. ${ }^{14}$ We have experimented more specifications than those reported here, including different instruments in model D. In particular, we find some sensitivity to the choice of instruments, in a similar way as in GMM estimations. As reported in Table 2, we can see for instance that the much smaller share for men in model D, compared to models $\mathrm{A}-\mathrm{C}$, is compensated by larger scale economies. This type of substitution is more or less strong depending on the instruments at use. Estimations are also less stable when the residuals of a first-stage estimation are included, since they enter linearly in the household budget share functions together with the different constants of the model (preferences and scale economies). ${ }^{15}$

Turning to estimates for couples with one young child, we find similar results, with scale economies between 0.53 and 0.84 for men and 0.48 and 0.73 for women over all the models that we have experimented with. One would expect that scale economies increase (i.e., that deflators decrease) in families compared to childless couples. Our results point in this direction for most of the specifications reported in Table 2, with the exception of males in models B and D. Yet, standard errors are even larger than in the case of childless couples, probably due to the more difficult identification of the model with children.

The estimates of the resource shares $\eta$ are more precisely estimated. For childless couples, the wife's resource share ranges from 0.51 to 0.63 across models with a standard error around 0.07.16 The effect of demographic variables on the sharing rule was also investigated but the sign and significance of the coefficients on age and education vary when we introduce the correction for endogeneity in model D. The only stable result is that higher male education plays in favour of a larger resource share for men. The share of children -interpreted as the cost of children - is relatively stable across specifications without endogeneity correction. In this case, we find an average share around 20 per cent, with no significant difference between boys and

\footnotetext{
13 These authors report deflators between 0.74 and 0.86 for men and 0.53 and 0.79 for women over the different models.

${ }^{14}$ Note that the standard errors reported in Table 2 are not so informative since economies of scale are nonlinear (exponential) transformation of the original coefficients.

15 To vary instruments in the first stage estimation of log expenditure, we have replaced household gross income by disposable income, and tried cubic specifications rather than quadratic ones.

${ }^{16}$ Browning et al. (2006) report a female share in excess of 0.60 while Lewbel and Pendakur (2008) report a female share between 0.36 and 0.46 with a standard error of 0.08 .
} 
girls. Model C is a simpler variant with no scale economies, which results in slightly more precise estimates of the remaining coefficients and in particular of the sharing rule. In this model, point estimates of children's shares are smaller, namely 16.5 per cent for boys and 17.5 per cent for girls. In model D, where endogeneity of total expenditure is controlled for, we find a significantly larger share for boys. Interestingly with this variant, the wage ratio (ratio of female to male wages) plays positively and significantly on the share of children. This is in line with previous results that mothers are more altruistic toward their children than fathers (see for instance Lundberg et al., 1997).

\subsection{Interpretations and Comparisons}

It is not surprising to find that the cost of children is larger in models AB-D than in model C. Indeed, the interpretation of child costs in these models incorporates the fact that parents are implicitly compensated by larger scale economies due to the presence of children (part of the child's consumption is joint). In other words, the changes in the structure of consumption when the size of the family increases can be attributed to economies of scale (and not only to the sharing rule). For these models, our estimations of the cost of children are around 20 per cent of household total expenditure. For model C, the cost of children is smaller than for the other models and often more similar to what is reported in previous studies based on traditional Rothbarth methods ${ }^{17}$ (however, not systematically, as seen below). Even if, in our opinion, the estimations obtained with models A-B-D are more realistic than what is generally reported, there are reasons to believe that these estimations still understate the true values of the cost of children. Indeed, the time devoted by parents to childcare, which certainly represents a significant fraction of nonmarket time, is not incorporated in our model. In particular, the mothers' parttime participation in the labour market that we observe in the data may well be associated with the provision of childcare. To account for childcare, future work should certainly incorporate labour supply decisions.

Before examining other estimations of child costs for Ireland, we can also compute indifference scales, interpreted as the scale to household income that puts a single individual on the same indifference curve as if living in couple. Indifference scales are equal to the scale economy deflator divided by the resource share. At the sample mean and for model B, the indifference scale of a woman in a childless couple is $0.61 / 0.55=1.11$. This implies that such a woman, if living alone, would need $1 / 1.11 \simeq 90$ per cent of the couple's income to reach the same indifference curve as when in a couple. This is clearly larger than a half because the single woman would not benefit from scale economies. In comparison, she would need 80 per cent of total expenditure, when alone,

\footnotetext{
17 See Deaton and Muellbauer (1986) and Gronau (1991) for instance.
} 
to be as well off as when in a couple with a little girl. The 10-percentage point difference compared to the childless couple situation reflects the loss of welfare due to sharing, mitigated by the additional scale economies due to the presence of the child. Hence, with model B, the effective cost of a girl is only 10 per cent (16 per cent) of total expenditure from the viewpoint of the mother (father); the effective cost of a boy is 12 per cent (13 per cent) for the mother (father). The interpretation of model $\mathrm{C}$ is different; the resource shares for adults measure directly their (money-metric) utility. In this model, there is no scale economy and a woman alone would need only 45 per cent of the couple's income to reach the same indifference curve when in a family with a girl. This figure seems excessively small.

To continue we present some elements of comparison with previous findings for Ireland. The cost of children in this country and the links to family policies have been studied in several papers, including Conniffe and Keogh (1988), Carney et al. (1994), Nolan (1999), Cantillon and Nolan (2001), Corrigan (2002), Cantillon et al. (2004) and Garvey (2007). Closest to our present approach, Garvey (2007) suggests an application of traditional Engel and Rothbarth methods to Irish household budget surveys (years 1994 and 1999). He documents a larger cost of children in urban areas and a larger cost for boys compared to girls. We confirm the latter result in our specification D only, but find in general relatively comparable results for boys and girls.

Table 3: Cost of Children: Comparisons

\begin{tabular}{|c|c|c|c|c|c|c|}
\hline \multicolumn{3}{|c|}{ Garvey (2007) } & \multicolumn{4}{|c|}{ Present Study } \\
\hline \multicolumn{3}{|l|}{ Rothbarth Model } & \multicolumn{4}{|c|}{ Model C+ } \\
\hline girl & $25 \%$ & 0.12 & Girl & $25 \%$ & 0.13 & $(0.03)$ \\
\hline Girl & Median & 0.12 & Girl & Median & 0.15 & $(0.04)$ \\
\hline Girl & $75 \%$ & 0.11 & Girl & $75 \%$ & 0.18 & $(0.04)$ \\
\hline Boy & $25 \%$ & 0.15 & Boy & $25 \%$ & 0.12 & $(0.03)$ \\
\hline Boy & Median & 0.16 & Boy & Median & 0.14 & $(0.03)$ \\
\hline \multirow[t]{8}{*}{ Boy } & $75 \%$ & 0.18 & Boy & $75 \%$ & 0.17 & $(0.04)$ \\
\hline & & & \multicolumn{4}{|c|}{ Model B+ } \\
\hline & & & Girl & $25 \%$ & 0.14 & $(0.05)$ \\
\hline & & & Girl & Median & 0.16 & $(0.06)$ \\
\hline & & & Girl & $75 \%$ & 0.18 & $(0.07)$ \\
\hline & & & Boy & $25 \%$ & 0.13 & $(0.05)$ \\
\hline & & & Boy & Median & 0.15 & $(0.06)$ \\
\hline & & & Boy & $75 \%$ & 0.17 & $(0.06)$ \\
\hline
\end{tabular}

Note: all tables report the resource share of children aged 0-4. Standard errors in bracket. Model C+ is similar to the Rothbarth's approach of Gronau (1991) while model $\mathrm{B}+$ incorporates scale economies. 
Garvey's results are reported at a different point of the distribution of household gross income. For comparability purposes, and to look at possible variations in the cost of children along the distribution, we then suggest a variant of our Rothbarth model $\mathrm{C}$, denoted $\mathrm{C}+$, where the sharing rule varies quadratically with household gross income; ${ }^{18}$ this way, we partly relax assumption A.2, as discussed previously. As shown in Table 3, we find slightly larger (smaller) costs for girls (boys) at the median compared to Garvey's application of the Rothbarth approach; yet, with standard errors around .04, we cannot reject that results are similar across studies. The results of these two studies indeed provide a relatively large confidence interval that contains results from older/other sources. For instance, Conniffe et al. (1999) estimate the cost of children using a combination of income and deprivation measures across a number of basic items. They estimate a cost around 13 per cent of household income for a child aged under five years in a two-adult family. Using the Household Budget Survey 1980 and an equivalence scale approach, Conniffe and Keogh (1988) find a cost around 12 per cent for this type of household. ${ }^{19}$

We also consider a variant of model $\mathrm{B}$, denoted $\mathrm{B}+$, where the sharing rule varies quadratically with income. The cost of children increases in this case, especially in the first half of the distribution. However, as explained above, the interpretation is slightly different since model $\mathrm{B}+$ now accounts for larger actual resources due to scale economies.

Finally, our results and Garvey's results for boys point toward larger costs of children (as a proportion of total resources) in richer households. ${ }^{20} \mathrm{We}$ also find a convex relationship between child cost and household income: child cost increases more between the median and the 75 th decile than between the 25 th decile and the median. Results thus seem to indicate that the dispersion of

\footnotetext{
${ }^{18}$ Household gross income is the sum of labour and capital income received by adults before taxes and benefits. Note that results are very similar when it is replaced by household disposable income. Also notice that we are not talking about equivalised income as we are looking at an homogenous population (couples with a young child).

${ }^{19}$ Some other approaches are know to overestimate child costs, like the Engel approach. Using this method, Garvey (2007) finds a weight of 0.15 at the 25 th centile, 0.18 at the median and 0.20 at the 75 th centile for children under five years. Note also that the McClements equivalence scale used by policy makers in the UK attributes a weight of 0.18 to a four-year-old child in a two-adult household. The modified OECD scale gives higher weights (0.30) to children, defined by being under 14 years of age, but does not account for different weights according to age (and in particular for smaller weights for younger children).

20 This contradicts the argument of Conniffe (1992), but the author finds smaller child resource share under the questionable assumption that public goods are luxury goods. Goods like housing costs are usually seen as necessities so that the share of private consumption, and in particular expenditures on children, may well be higher in higher income families. Note also that in our estimation, the income effect is obtained for a constant level of expenditure.
} 
'child resources' is larger than that of household income. If a poor child is defined as receiving a share below 60 per cent of the median share, rather than as living in a household with income below 60 per cent of the median household income, then a larger spread in child resource could signify that some poor children (according to the former definition) live in non-poor families (according to the latter definition). ${ }^{21}$ At this stage, however, our exercise is more illustrative than of practical use for policies aimed at combating child poverty. Indeed, we have focused on a group less at risk of child poverty - families with one young child and, most importantly, on twoearner couples - while poverty concerns mostly children of lone parents, large families and families with unemployed parents (Nolan, 1999). While accounting for families with several children is in principle easy under certain additional assumption (Bargain and Donni, 2009), future research should address parent's labour supply decision within the present framework.

\section{CONCLUSION}

This paper suggests a measure of the cost of children for Ireland based on the approach proposed in Bargain and Donni (2009). Economies of scale are accounted for in a simple way thanks to an Independence of Base assumption and can be recovered using information on single individuals. The identification of the child's share of resources also requires the observation of expenditure on adult goods, as in the traditional Rothbarth approach. We conduct the estimation on a pooled sample of single individuals, childless couples and couples with one child, using cross-sectional expenditure data for Ireland. Even though the estimates of scale economies are very imprecise, we find relatively stable and more precise results for the cost of children. Comparison with the standard Rothbarth method also convey that economies of scale are an important element that should not be ignored when modelling and estimating the redistributive process within households.

In the last section, we have sketched the possibilities offered by the present framework to study child poverty in an innovative way, i.e., by considering the share of resources accruing to children and evaluating child financial poverty on this basis. We have also stressed the fact that the present framework needs important extensions and especially the explicit modelling of

21 This result is consistent with alternative assessments of child poverty based on direct measures of child deprivation; in particular, Cantillon et al. (2004) show that a significant minority of those reporting some child deprivation are in households above the 60 per cent income threshold, and so would not be counted as poor even by the most generous relative income line. 
parents' labour supply decisions. Without this, it is not possible to account for households in which children are most at risk of poverty nor to address the endogeneity of total expenditure to adults' labour supply choices. An alternative and simpler way could make use of demands conditional on female participation in the labour market. However, modelling labour supply decisions is necessary to measure the complete cost of children, including the cost of the parents' temporary retirement from the labour market for childcare.

The theoretical model must also been refined. For instance, it is not clear how our model can account for changes in preferences and externalities in consumption that are likely induced by children. Another interesting path for future research is the comparison between the present microeconomic model and direct measures of child deprivation as provided in recent surveys like Cantillon and Nolan (2001) and Cantillon et al. (2004). Finally, new measures of the cost of children should be discussed in the light of existing policies. For instance, Corrigan (2002) assesses the relative generosity of Ireland's child benefit package and its adequacy with respect to child poverty rates and estimates of the cost of children. Garvey (2007) compares the estimated cost of children to the weight put on children in different policy instruments (primarily family benefits).

\section{REFERENCES}

BANKS, J., R. W. BLUNDELL and A. LEWBEL, A., 1997. "Quadratic Engel Curves and Consumer Demand", Review of Economics and Statistics, Vol. 79, No. 4, pp. 527-539.

BARGAIN, O. and O. DONNI, 2008. "Indirect Taxation, Targeting, and Child Poverty", mimeo.

BARGAIN, O. and O. DONNI, 2009. "The Measurement of Child Costs: A RothbarthType Method Consistent with Scale Economies", mimeo.

BARTEN, A. P., 1964. "Family Composition, Prices, and Expenditure Patterns" in P. Hart, G. Mills and J. K. Whitaker (eds.), Econometric Analysis for National Economic Planning: 16th Symposium of the Colston Society, pp. 277-292, London: Butterworth.

BLUNDELL, R. and J-M. ROBIN, 1999. "Estimation in Large and Disaggregated Demand Systems: An Estimator for Conditionally Linear Systems", Journal of Applied Econometrics, Vol. 14, pp. 209-232.

BLUNDELL, R. and J-M. ROBIN, 2000. "Latent Separability: Grouping Goods Without Weak Separability”, Econometrica, Vol. 68, No. 1, pp. 53-84.

BLUNDELL, R., P.-A. CHIAPPORI and C. MEGHIR, 2005. "Collective Labor Supply with Children”, Journal of Political Economy, Vol. 113, No. 6, pp. 1277-1306.

BOURGUIGNON, F., 1999. "The Cost of Children: May the Collective Approach to Household Behaviour Help?", Journal of Population Economics, Vol. 12, No. 4, pp. 503-522. 
BROWNING, M., 1992. "Children and Household Economic Behavior", Journal of Economic Literature, Vol. 30, pp. 1434-1475.

BROWNING, M., P.-A. CHIAPPORI and A. LEWBEL, 2006. "Estimating Consumption Economies of Scale, Adult Equivalence Scales, and Household Bargaining Power", Boston College Working Paper in Economics 588.

CALLAN, T., K. COLEMAN, B. NOLAN and J. R. WALSH, 2007. "Child Poverty and Child Income Supports: Ireland in Comparative Perspective", Budget Perspectives 2007, Dublin: Economic and Social Research Institute.

CANTILLON, S. and B. NOLAN, 2001. "Poverty Within Households: Measuring Gender Differences Using Non Monetary Indicators", Feminist Economics, Vol. 7, No. 1.

CANTILLON, S., B. GANNON and B. NOLAN, 2004. "Sharing Household Resources: Learning from Non-Monetary Indicators", Dublin: Combat Poverty Agency.

CARNEY, C., E. FITZGERALD, G. KIELY and P. QUINN, 1994. "The Cost of a Child: A Report on the Financial Cost of Child-Rearing in Ireland", Dublin: Combat Poverty Agency.

CENTRAL STATISTICS OFFICE, 2006. Measuring Ireland's Progress 2005, Dublin: Central Statistics Office.

CHIAPPORI, P.-A. and O. DONNI, 2010. Non-Unitary Models of Household Behavior: A Survey of the Literature in A. Molina (ed.), Household Economic Behaviors, Berlin: Springer.

CONNIFFE, D., 1992. "The Non-constancy of Equivalence Scales", Review of Income and Wealth, Vol. 38, No. 4, pp. 429-443.

CONNIFFE, D. and G. KEOGH, 1988. Equivalence Scales and Costs of Children, Dublin: Economic and Social Research Institute.

CONNIFFE, D., B. NOLAN and C. T. WHELAN, 1999. "Household Composition, Living Standards and 'Needs"”, Working Paper No. 106, Dublin: Economic and Social Research Institute.

CORRIGAN, C., 2002. "Exploring an Income Adequacy Standard for Children”, Combat Poverty Agency, Working Paper 04/02.

DEATON, A. S. and J. MUELLBAUER, 1986. "On Measuring Child Costs: With Applications to Poor Countries”, The Journal of Political Economy, Vol. 94, No. 4, pp. $720-744$.

DONNI O., 2008. "Collective Models of the Household" in L. Blume and S. Durlauf (eds.), The New Palgrave Dictionary of Economics, 2nd Edition. London: Palgrave McMillan.

GARVEY, E., 2007. "Cost of Children: An Economic Perspective", Dublin: Combat Poverty Agency, research working paper.

GRONAU, R., 1988. "Consumption Technology and the Intrafamily Distribution of Resources: Adult Equivalence Scales Reexamined”, Journal of Political Economy, Vol. 96, No. 6, pp. 1183-1205.

GRONAU, R., 1991. "The Intrafamily Allocation of Goods - How to Separate the Adult from the Child", Journal of Labor Economics, Vol. 9, No. 3, pp. 207-235.

LAZEAR, E. P. and R .T. MICHAEL, 1988. "Allocation of Income within the Household", Chicago: University of Chicago Press.

LEWBEL, A., 1997. "Consumer Demand Systems and Household Equivalence Scales" in M. H. Pesaran and P. Schmidt (eds.), Handbook of Applied Econometrics, Volume II: Microeconomics, Oxford: Blackwell Publishers Ltd. 
LEWBEL, A., 2003. "Calculating Compensation in Cases of Wrongful Death", Journal of Econometrics, Vol. 113, pp. 115-128.

LEWBEL, A. and K. PENDAKUR, 2008. "Estimation of Collective Household Models with Engel Curves", Journal of Econometrics, Vol. 147, No. 2, pp. 350-358.

LUNDBERG S. J., R. A. POLLAK and T. J. WALES, 1997. "Do Husbands and Wives Pool Their Resources? Evidence from the U.K. Child Benefit", Journal of Human Resources, Vol. 32, No. 3, pp. 463-480.

MENON, M. and F. PERALI, 2007. "The Cost of Rearing Children, Child Welfare and Child Poverty Within the Collective Household Model", mimeo.

MICKLEWRIGHT, J., 2004. "Child Poverty in English Speaking Countries", IZA Discussion Paper No. 1113, April.

NOLAN, B., 1999. "Child Poverty in Ireland, Dublin: Report to Combat Poverty Agency.

NOLAN, B., R. LAYTE, B. MAITRE and C. T. WHELAN, 2006. "Day In, Day Out: Understanding the Dynamics of Child Poverty in Ireland", Dublin: Institute of Public Administration/Combat Poverty Agency.

OFFICE OF THE MINISTER FOR CHILDREN, 2006. State of the Nation's Children, Dublin: Stationery Office.

PENDAKUR, K., 1999. "Estimates and Tests of Base-Independent Equivalence Scales", Journal of Econometrics, Vol. 88, pp. 1-40.

POLLAK, R. and T. J. WALES, 1992. Demand System Specification and Estimation, New York: Oxford University Press.

ROTHBARTH, E., 1943. "Note on a Method of Determining Equivalent Income for Families of Different Composition" in C. Madge (ed.), War-time Pattern of Saving and Spending, Cambridge: Cambridge University Press. 